\title{
Web Based Educational Seminars Compare Favorably with In-house Seminars for Bariatric Surgery Patients
}

Sara Monfared MDa, Anna Martin ${ }^{b}$, Kamna Guptac, Dimitrios Stefanidis MD PhDa, Don Selzer $M D^{a}$, Jennifer Choi MDa, Annabelle Butler MDa, Ambar Banerjee MDa

${ }^{a}$ Department of Surgery, Division of Bariatric and Minimally Invasive Surgery, Indiana University School of Medicine

${ }^{\mathrm{b}}$ Indiana University and Purdue University School of Sciences

${ }^{\mathrm{c}}$ Indiana University School of Liberal Arts

Corresponding author:

Sara Monfared

545 Barnhill Drive, Emerson Hall 122

Indianapolis, Indiana 46202

Telephone: 216-849-6804

Fax: 317-274-8769

Email: smonfare@iupui.edu

\section{Disclosures}

There was no funding for this project.

Drs. Butler, Choi and Banerjee have no conflicts of interest or financial ties to disclose. Anna Martin and Kamna Gupta have no conflicts of interest or financial ties to disclose.

Drs. Monfared and Stefanidis have research support from ExplORer Surgical however none of the research in the present report was funded by the above.

Dr. Selzer is a consultant for Cook Biotech and PolyNovo, and has research support from Bard Mesh. However, none of the research in the present report was funded by the above.

This is the author's manuscript of the article published in final edited form as:

Monfared, S., Martin, A., Gupta, K., Stefanidis, D., Selzer, D., Choi, J., ... Banerjee, A. (2019). Web-Based Educational Seminars Compare Favorably with In-House Seminars for Bariatric Surgery Patients. Obesity Surgery, 29(3), 878-881. https://doi.org/10.1007/s11695-018-3590-4 


\begin{abstract}
Background: Comprehensive preparative patient education is a key element in bariatric patient success. The primary objective of this study was to compare attrition rates, demographics and surgery outcomes between patients who participated in the online vs in-house preparative seminars.
\end{abstract}

Methods: A retrospective chart review was performed involving patients who chose to participate in online vs in-house educational seminar between July of 2014 and December of 2016. The patients were divided into two groups based on their choice of educational seminar and tracked to see how many made it to an initial visit and to surgery. In those who had bariatric surgery, data was collected on age, type of insurance, length of stay (LOS), longest follow up and change in body mass index.

Results: Total of 1230 patients were included in this study. There was no difference in attrition rate to initial consultation visit ( $29.1 \%$ vs $29.9 \%$ ) but there was a statistically higher attrition to surgery in the inhouse seminar attendees $(72.9 \%)$ compared to online participants $(66.6 \%, p<0.05)$. Between January 2015 and December 2016, 291 patients underwent primary bariatric surgery. The online group was on average 3 years younger which was statistically significant. There was no differences in LOS, longest follow up and weight loss at 12 months between the groups.

Conclusion: When comparing attrition rates and bariatric surgery outcomes, no overall difference was noted between patients who received web or hospital based preparative education. Bariatric programs should provide access to online seminars to attract younger population, save resources and cost.

Keywords: Online Seminar, web based seminar, live seminar, patient education, Bariatric surgery 


\section{Introduction}

Bariatric surgery requires lifelong commitment. Preoperative education is important to helping patients prepare for surgery and achieve optimal success (1) by helping them understand how weight loss surgery works, its benefits and risks, the necessity of long term follow up and the potential for weight regain. Traditionally, initial patient education had been achieved by in-person group presentations with bariatric surgeons and other support staff. In-person seminars can be inconvenient to attend and they may deter patients who feel ashamed by their weight.

Given that as of $2018,89 \%$ of U.S. adults use the internet (2) and according to 2015 national census, $87 \%$ of households have at least one computer and/or handheld device(3), it may be prudent to limit inhouse, live informational seminars and offer online seminars for the education of obese patients considering bariatric surgery. Web-based sessions are flexible to work schedules as they can be completed anywhere and at any time. Furthermore, they are cost effective, available for review, more attractive to younger generation and sensitive to the needs of those with limited mobility and outside of practice's usual geographic area (4). Nevertheless, very few studies have examined the role of online seminars in the education of patients seeking bariatric surgery $(4,5)$. It is important to demonstrate the effectiveness of this approach before recommending it for wide use.

The primary objective of our study was to compare attrition rates to surgery as well as postoperative outcomes between patients who participated in the online vs in-house preparative seminars.

\section{Materials and Methods}

After obtaining Institutional Review Board approval, retrospective analysis was performed on patients who participated in an educational seminar at a Bariatric Surgery Center of Excellence. Prospective patients who desired weight loss surgery were required to attend one educational seminar and complete a health history packet before they were scheduled for a consultation with a surgeon. The purpose of the session was to teach the patients about obesity, bariatric surgery, risks, benefits, program requirements, and insurance approval process. The patients could register through the telephone or email to attend one of our in-house seminars lead by a bariatric surgeon and two clinical nurses. The in-house seminars occurred 2-3 times per month on Saturday mornings at our center, and following the 2-hour information session, patients completed a quiz. Those who chose to partake in the online seminar received an email with instructions on how to access the educational video and quiz which could be viewed on a computer or handheld device. The information given in the live and online seminars were the same but the patients who took the online seminar, understandably, could not ask questions immediately. After completing the online seminar, they may email or call with questions and were encouraged to bring them to their first consultation. Our patients were required to pass the quiz in either session with a score of $80 \%$ or above in order to grasp the key components of metabolic surgery. Quiz results were also reviewed with patients during their initial consultation to ensure understanding.

The online seminar was offered at our institution starting July of 2014. Therefore, we obtained the handwritten, sign-in sheets from the in-house seminars and the typed-out list of people who took the online seminar from July of 2014 to December of 2016. We included at least a one year follow up after surgery. We excluded patients who had a history of bariatric surgery and were seeking revisional surgery. Patients were excluded if they attended both in-house and online seminars and if their name could not be deciphered from hand-written, sign-in sheets. Patients were divided into two groups, online vs in- 
house, and their progress in our program was tracked via chart review from their initial office visit with one of our surgeons to after surgery. Our primary outcome was patient attrition rate from seminar to initial office visit and from seminar to surgery. For our secondary outcomes, we looked at those who had surgery between January of 2015 to December of 2016 and data was collected on age, type of insurance, initial body mass index (BMI), length of hospital stay (LOS) in days, longest follow up (f/u) in months and change in BMI postoperatively.

\section{Data analysis}

In our study, $x^{2}$ test was used to compare attrition from seminar to initial office visit and attrition from seminar to surgery between in-house and online groups (Table 1). Next we used independent sample $t$ test and $x^{2}$ test as appropriate to compare demographics including age, type of surgery, initial BMI and type of insurance among those who had an operation (Table 2). Finally, independent $t$ test and multivariable regression analysis controlling for potential confounders (age, type of surgery, and type of procedure) were done for the postoperative outcome mean comparisons between in-house and online groups (Table 3).

Two metrics were applied to assess postoperative weight loss: Change in $\mathrm{BMI}(\triangle \mathrm{BMI})=$ Preoperative $\mathrm{BMI}$ - Postoperative BMI (6 or 12 month follow up) and Percent change in $\mathrm{BMI}(\% \Delta \mathrm{BMI})=(\Delta \mathrm{BMI} /$ Preoperative BMI) $\times 100$.

The level of significance was $\alpha=0.05$, will all p-values $<0.05$ considered statistically significant. Statistical analyses were done on IBM SPSS Statistics (Version 24.0).

\section{Results}

Total of 1330 prospective patients completed bariatric educational seminars between July 1, 2014 and December 31, 2016. Ninety-eight patients were excluded because their names were not legible on the sign in sheets and 2 patients were excluded because they attended both seminars leaving 1230 patients included in our study. The in-house group had 656 attendees (53.3\%) and online group had 574 attendees (46.7\%). Table 1 shows the attrition rate throughput from seminar to office to surgery. There was no difference between the attrition rate from seminar to office visit between the two groups $(p=0.76)$. However there was a statistically higher attrition rate of patients from seminar to surgery in those who attended the in-house seminar $(p=0.02)$.

Two hundred and ninety one patients underwent primary bariatric surgery between January 1, 2015 and December 31, 2016. Of that total, 115 were in the online group and 176 were in the in-house group. Demographics of the surgical patients are shown in Table 2. Privately insured patients favored the online group (73\%) versus $61.4 \%$ in the in-house group but did not reach statistical significance ( $P=0.12)$.

Patients choosing online seminar were 3 years younger than those who went to the in-house seminar $(p=0.017)$. Prospective patients in the online group were statistically more likely to undergo sleeve gastrectomy ( $40.9 \%$ online vs $27.3 \%$ in house) as opposed to those in the in-house group who were more likely to undergo gastric bypass $(72.7 \%$ in-house vs $59.1 \%$; $p=0.02)$.

The average Initial BMI of patients undergoing surgery was $45.5 \pm 7.4 \mathrm{~kg} / \mathrm{m}^{2}$ and dropped to $32.7 \pm 6.6$ $\mathrm{kg} / \mathrm{m}^{2}$ at 12 months post-surgery $(p<0.001)$. 
The comparison of postoperative outcomes between our two groups is demonstrated in Table 3. There was no statistical difference in length of stay among the two groups. In addition, there was no difference in change in BMI or percent change in BMI at 6 month or 12 month postoperatively. Even after adjusting for age, type of surgery, and type of insurance in our multivariable regression analysis, there was no significant difference in LOS and change in BMI. Patients in the in-house seminar group were found to follow-up longer $(14.0 \pm 7.0)$ than patients in the online group $(11.9 \pm 7.0)$ in our bivariate analysis $(p=0.01)$. But after adjusting for our potential confounders, this became non-significant in multivariable analysis $(p=0.06)$.

\section{Discussion}

The results of this study demonstrated that there was no difference in attrition percentage from seminar to initial consultation between those who took the online seminar vs in-house seminar. On the other hand, there was a lower attrition rate from seminar to surgery among those who chose the online seminars. These findings are opposite to those reported in Miletics et al (5). They stated that a statistically higher percentage of patients made it to the office visit and to surgery among the live seminar attendees compared to online participants. A reason for our conflicting findings may be that Miletics and colleagues analyzed data from 2011 to 2015 (5) and our data was from 2014 to 2016. With access and use of technology increasing substantially every year, recent patients may have preferred online seminars. It would be interesting to compare only the years we overlap. It is important to note that patients who are seen after an initial visit may be denied surgery or do not finish the preoperative program for a multitude of reasons that can confound the attrition or progression percentages reported in both studies. However, the proportions reported from seminar to first office visit are likely less confounded and do demonstrate, in our results, that prospective patients from either group are equally determined to follow through with a consultation.

The online seminar participants were on average younger which is consistent with previously reported literature $(4,5)$. However, while national surveys have shown that the younger generation are more likely to search for health information online(6), this three-year age difference may be of limited clinical value and may not reflect a generational age gap in our patient population. There was no difference in postoperative outcomes in regards to length of stay, follow up, and change in $\mathrm{BMI}$, which is again consistent with other published research (4). The type of seminar, which the patients choose, does not change their degree of success with surgery. It is critical to note that education has to be delivered to the bariatric surgery patient in an ongoing fashion and not limited to one single seminar session in order to affect behavioral changes, and this is certainly the approach in our program. We feel that multiple educational encounters effectively provide our patients with the necessary preparation prior to and after bariatric surgery to be successful.

In our institution, the overtime cost for ancillary staff is approximately $\$ 171.45$ per session of an inhouse seminar. It also requires an up to 2-hour commitment on Saturday mornings from our surgeons. In contrast, the online seminars had no production or maintenance costs as well as no extra time commitment from our staff. Given the increase in staff responsibilities and time constraints, bariatric centers should move towards web-based education. Our institution has decreased its in-house seminars by one per month due to our results. While we noticed a minor decrease in in-house seminar participation, the overall attendance increased by $41 \%$ after the addition of online seminars. We will follow this trend over time to see if it holds true. Integration of information about bariatric surgery into an online system is an excellent method to remain competitive and relevant to the customer. 
Internet use by Americans today is pervasive and extends also to their healthcare needs. In $2012,72 \%$ of US adult internet users have looked online for health information (6). The patient sub-groups, who are most likely to search online for health information, are women, whites, aged between 18-49 years and those with insurance(6). These demographics precisely overlap with a standard bariatric patient (7). Therefore it is crucial to advocate for web-based education and information for the prospective surgical patient.

Even though we have demonstrated the importance of online education, our study had limitations. The live-seminar patients signed in by hand and those patients whose name could not be deciphered were excluded and could have affected the attrition rate. As noted above, the attrition to surgery may have been confounded by other factors such as choice of operation. Future targeted studies are needed to address these issues and assess if there is an inherent bias of each seminar session. Finally, we did not have any demographics on the initial patients who took the seminars and if age or type of insurance may have affected the throughput results.

In conclusion, bariatric centers of excellence may benefit from providing online education to their patients as in this study it appears to be as effective as in-person seminars with several other additional advantages. In-house seminars should be continued to reach the $11 \%$ of people (2) who do not have internet access or those who prefer live interaction. Future studies should look at patient demographic trends of those who choose online versus live educational forum to target a more specific audience.

\section{References}

\section{References}

1. Garza SF. Bariatric weight loss surgery: patient education, preparation, and follow-up. Critical Care Nursing Quarterly. 2003;26(2):101-4. PubMed PMID: 106844091. Language: English. Entry Date: 20030627. Revision Date: 20150818. Publication Type: Journal Article. Journal Subset: Core Nursing. 2. Internet/broadband fact sheet. Washington, DC: Pew Research Center; 2018 [updated February 5, 2018]; Available from: http://www.pewinternet.org/fact-sheet/internet-broadband/.

3. Ryan C, Lewis JM. Computer and Internet Use in the United States: 2015. Washington, DC: American Community Survey Reports, US Census Bureau; 2017 [updated October 24, 2017]; Available from: https://www.census.gov/library/publications/2017/acs/acs-37.html.

4. Eaton L, Walsh C, Magnuson T, Schweitzer M, Lidor A, Nguyen H, et al. On-line bariatric surgery information session as effective as in-person information session. Surg Obes Relat Dis. 2012 MarApr;8(2):225-9; discussion 9. PubMed PMID: 22178563.

5. Miletics M, Claros L, Stoltzfus J, Davis T, Chaar ME. Progression to surgery: online versus live seminar. Surg Obes Relat Dis. 2018 Mar;14(3):382-5. PubMed PMID: 29275094.

6. $\quad$ Fox S, Duggan M. Health online 2013. Health. 2013;2013:1-55.

7. Pratt GM, Learn CA, Hughes GD, Clark BL, Warthen M, Pories W. Demographics and outcomes at American Society for Metabolic and Bariatric Surgery Centers of Excellence. Surg Endosc. 2009 Apr;23(4):795-9. PubMed PMID: 19184200. 
Table 1 Attrition proportion from seminar to initial office visit and seminar to surgery

\begin{tabular}{lccc}
\hline & Online & In-House & P-value \\
\hline Seminar to Office & $167 / 574(29.1 \%)$ & $196 / 656(29.9 \%)$ & 0.764 \\
Seminar to Surgery & $382 / 574(66.6 \%)$ & $478 / 656(72.9 \%)$ & 0.016 \\
\hline
\end{tabular}

Table 2 Patient Demographic Characteristics

\begin{tabular}{|c|c|c|c|}
\hline Variables & Online & In-House & P-value \\
\hline Total per seminar group $(n=291)$ & $N=115$ & $N=176$ & \\
\hline \multicolumn{4}{|l|}{ Type of Surgery } \\
\hline Roux-en Y Gastric Bypass, \% (n) & $59.1 \%(68)$ & $72.7 \%(128)$ & \multirow{2}{*}{0.016} \\
\hline Sleeve Gastrectomy, \% (n) & $40.9 \%(47)$ & $27.3 \%(48)$ & \\
\hline \multicolumn{4}{|l|}{ Insurance Type, \% (n) } \\
\hline Private & $73.0 \%(84)$ & $61.4 \%(108)$ & \multirow{3}{*}{0.115} \\
\hline Medicaid & $15.7 \%(18)$ & $21.0 \%(37)$ & \\
\hline Medicare & $11.3 \%(13)$ & $17.6 \%(31)$ & \\
\hline Age, years, Mean \pm SD & $44.2 \pm 11.2$ & $47.4 \pm 10.7$ & 0.017 \\
\hline Initial BMI kg/m² & $44.9 \pm 6.1$ & $45.7 \pm 8.1$ & 0.360 \\
\hline
\end{tabular}

$\mathrm{BMI}$, body mass index

Table 3 Postoperative Outcomes Comparisons

\begin{tabular}{|c|c|c|c|c|}
\hline Variables & Online & In-House & P-value ${ }^{\text {a }}$ & P-value ${ }^{b}$ \\
\hline LOS, days, Mean \pm SD & $1.89 \pm 1.6$ & $2.13 \pm 2.1$ & 0.290 & 0.688 \\
\hline Longest $\mathrm{f} / \mathrm{u}$, months Mean $\pm \mathrm{SD}$ & $11.9 \pm 7.0$ & $14.0 \pm 7.0$ & 0.012 & 0.055 \\
\hline \multicolumn{5}{|l|}{6 Month Change in BMI } \\
\hline$\Delta \mathrm{BMI}, \mathrm{kg} / \mathrm{m}^{2}$, Mean $\pm \mathrm{SD}^{\mathrm{c}}$ & $10.1 \pm 2.7$ & $10.3 \pm 3.4$ & 0.676 & 0.814 \\
\hline$\% \triangle \mathrm{BMI}$, Mean $\pm \mathrm{SD}^{\mathrm{c}}$ & $22.4 \pm 5.1$ & $22.6 \pm 6.9$ & 0.771 & 0.942 \\
\hline \multicolumn{5}{|l|}{12 Month Change in BMI } \\
\hline$\Delta \mathrm{BMI}, \mathrm{kg} / \mathrm{m}^{2}$, Mean $\pm \mathrm{SD}^{\mathrm{c}}$ & $12.6 \pm 4.7$ & $13.0 \pm 4.8$ & 0.531 & 0.919 \\
\hline$\% \Delta \mathrm{BMI}$, Mean $\pm \mathrm{SD}^{\mathrm{c}}$ & $27.5 \pm 8.4$ & $28.4 \pm 9.3$ & 0.504 & 0.752 \\
\hline
\end{tabular}

a P-value based on bivariate $t$-test analysis

${ }^{b} P$-value based on multivariable linear regression analysis controlling for age, surgery type and insurance type as potential confounders

${ }^{C}$ Calculated as change in BMI from preoperative to postoperative follow up month.

$B M I$, body mass index; F/u, follow up; LOS, length of stay; SD, standard deviation 